\title{
Transport Administration in Nigeria and Britain: Prospects, Issues and Recommendations
}

\author{
Dr Adeniyi Olufemi Oluwakoya \\ Department of Transport Management \\ Redeemer's University, Ede, Osun State \\ Dr Stephen Olufemi Obasa \\ Department of Political and Public Administration \\ Redeemer's University, Ede, Osun State
}

Received: Oct. 10, 2020 Accepted: Nov. 2, 2020 Online published: Nov. 18, 2020

doi:10.5296/jpag.v10i4.17956 URL: https://doi.org/10.5296/jpag.v10i4.17956

\begin{abstract}
Transport, due to its ubiquitous nature, takes a key position in contemporary discourse as a critical sector that impacts governance, economic and social wellbeing of the national development. The unprecedented transportation challenges, particularly in the sub-Saharan states, have a significant implication on the performance of their economies. These challenges, more often than not, are generated by disequilibrium in the policy of the government as it affects transport administration. The study takes a comparative evaluation of the extent, dimension and manner of transport administration in Nigeria and Britain. The approach involves a documentary search of the policy intervention of transport administration in both countries. The study identifies the issues and challenges of transport administration lapses, especially on the part of Nigeria and relevant recommendation to improve transport administration for national economic development.
\end{abstract}

\section{Introduction}

Transportation administration is the process of formulating plans, framing policies and setting objectives for the transport sector by the government, the intention of which is to make the best possible allocation of limited resources in the transportation sector, to enhance effectiveness and efficiency in service delivery. Since Transport creates an opportunity for its users to secure conveyance, it needs to provide for its patronage. Transportation and safety achieved through the development of policies, programmes, and projects. Adebisi (2004) uses 
the term management to mean a package of actions designed to optimise the available highway network in a well-focused manner.

The transport sector in every nation of the world is very significant to the growth of the economy both in the advanced and less advanced as it drives effective globalisation in trading if there is an appropriate institutional structure for that. Hence, it becomes imperative for every transportation issue to be considered paramount to a lot of countries who see it as a means by which they can compete globally and assist such to transform their slow domestic economy. In Muktar's view, mobility studies show that transportation is essential to economic productivity and remains competitive in the global marketplace (Muktar, 2011).

There are lots of revolutionary changes in technology in this era, such that any country that fails to flow with the contemporary trend left behind in the transportation industry in the global environment. These technologies have brought improvement in the transportation sector in the area of mobility, safety, efficiency, and convenience. Despite the new technologies, there are still issues serving affecting the industry. For instance, there are now automated cars, trucks, ship and aircraft tested by companies in the advanced countries. According to the Transportation Research Board (TRB, 2019), Pilot vehicles are already in operation. Some products are almost sure to enter the marketplace in the next few years. Driverless cars equipped with artificial intelligence may revolutionise transportation. Perhaps even sooner, vehicles connected with advanced high-speed communication technologies may significantly reduce crashes.

Ironically, the issue of transport administration affects nations globally in diverse forms as different factors are responsible for it aside from the improper implementation of transport policy. These range from an erroneous policy from the legislature, political interference from policymakers to misinterpretation of policy and selfish desires from the executive class. Perhaps factors like the inadequate supply of resources, the involvement of quack engineers in the contraction of transportation infrastructure, lack of maintenance of means of transportation on the part of users, bureaucratic factor and corruption among public servants and political leaders in power.

Despite the preceding, this study seeks to compare the nature, extent and dimension of transport administration in Nigeria and Britain. The essence is to improve on policy lapses and identify issues and challenges plaguing the Nigeria Transport sector. This study divides into five segments. The first section examines the nature and practices of Transport administration in Nigeria and the second section takes a look at the transport administration in the United Kingdom. The third sections comparatively look at the issues emanating from the practices of transport administration in both Nigeria and the United Kingdom. The fourth section makes a recommendation to improve transport administration in Nigeria, and the fifth section concludes on the feasible policy options.

\subsection{Research Theoretical Framework}

In comparative administration, there are theories such as system theory, structural-functionalism theory, bureaucratic theory, political culture theory, and prismatic 
model, among others used to explain administrative and political issues in different nations.

In this study, we have decided to use system theory to explain transportation phenomenon in Nigeria and Britain. We posit that the adequate performance of any transportation system in any society is a functioning system operating in such. The basis for adopting system theory as it focuses on the relationship, structure and interdependence of the various subsystems. The theory is a combination of interrelated parts which form a complex whole of any phenomenon. The conceptual origins of this theory generally linked to English Sociologist and Philosopher Herbert Spencer and French Social Scientist Emile Durheim in $19^{\text {th }}$ Century. Charles Darwin's theory of evolution influences both philosophers.

\subsection{Justification for Comparison}

Comparing Nigeria's transportation administration with Britain's own would enable us to know the similarities and dissimilarities that exist in their transportation systems. Aside from this, it would allow us to understand the reasons behind the success in the British transportation system and how we can explore that to promote Nigeria's system. Comparing the two countries would grant Nigeria the opportunity of learning new technologies from Britain. Besides, how those issues like inferior quality of networks, shortages and malfunctioning of transport equipment and furniture, lack of executive capacity and technically-qualified personnel, inadequate planning and coordination, insufficient capital and the legacy of unfortunate economic and political policies, continued concentration of transport development on intra and inter-city linkages and the relative neglect of rural Transport, institutional gridlocks, viii. efficient energy use (fuel shortages), safety, security and environmental issues, financing, research and technology, economic, financial and efficiency viability facing Nigeria's transportation has affected her transport industry and why Britain had been able to overcome such in the course of administering their transport system

\subsection{Scope}

The research area explored in this work contained the transportation systems in Nigeria and Britain. The parameters for comparing these two countries is to enable readers to understand factors responsible for success in the transportation systems in Britain so that Nigeria could use this to improve on her transport administration.

\subsection{Research Method}

The research method involves the mixed of documentary and archival secondary data search on the transport administration in both Nigeria and Britain. Majorly it considers provenance of Transport infrastructural problems and challenges on the bases of policy and planning implications and makes a comparison with the development of transport infrastructure in Britain. It is a qualitative representation of transport administration intervention in both countries. The perspective literature narratives form the bases of this study.

\section{Transportation Administration in Nigeria}

Responsibilities for transport administration in Nigeria dates back to the colonial era (Olukolu, 2013). The period marks a necessary intervention on the part of the colonial 
administrator for the quick provision of transport infrastructure to facilitate the evacuation of raw material and cash crops to feed the growing industries in Britain (Mabogunje,2015). Besides, the need to manage the communication and movements of colonial personnel among the different administrative centre necessitated the provision of roads from the central administrative centres to the district and local centres. Mostly, colonial transport administration in Nigeria lacks a holistic transportation developmental framework for the country, as transportation project engagement is at the whims and caprices of the colonial administration. And it is solely to satisfy the yearning and aspiration of the colonial administrator. The road infrastructure developed during this period; however, initiatives and legislations for port and harbour and railway development started during this period.

The post-colonial era of transport administration in Nigeria witness a change from the colonial to indigenous policy formulation. However, the policy transition remains constant as there is no real change and innovation from the practice of transport administration from the colonial to the post-colonial. The responsibilities of the transport administration structure established during the colonial period remain the same. For instance, after independence, the Minister of Transport assume the supervisory role of transportation providers in the country. However, during the period, the lack of a comprehensive framework for the development of transport infrastructure across the mode weakened the transport infrastructure development efforts in the country. The inability to create a comprehensive modal development framework contributed immensely to the retardation some of the modes suffer till date. Besides, the transport portfolio at the Federal Government level in the country has always been revolving around Ministry of Transport, Ministry of Transport and Aviation, Ministry of Works, Ministry of Works and Housing, Ministry of Works and Housing and Urban Development.

The political structure of transport administration in the country has always been the bane of Transport infrastructural development. The deficiency at the federal level has trickled down to the state and the local government. The federal and the state seem to share a similarity in the transport administration portfolio assignment, which lacks a holistic transport development framework. Of the three levels of government, the local government seems to be the worst in transport administration as the most local government lacks the transport infrastructure provision. This lapse is because of the lack of transport administration structure to formulate critical transport policy drive to improve flows within and outside the local government area. The existing political system marred with corruption. This problem reflected in the handling of the transport portfolio across the three levels of government. The most politician saddled with the head of the transport administration portfolio often colludes with the civil service structure of the transport ministry to siphon funds meant for transport infrastructure improvement projects. Moreover, most politicians saddled with the responsibility of managing transport administration at the federal, state and the local government lack relevant transport education and skills to deliver transport policy thrust for transport development.

In Africa, where foreign trade has expanded recently, just like in some other continents, transportation administration in the various countries has advanced. Likewise, in Nigeria, foreign trade has exposed the country's goods and services to other countries. Thus, road 
transportation is the most typical and most extensively used form of transportation. Over time, the road transportation system has been the primary mode of transportation in Nigeria aside from water, air and rail.

\section{Transportation Administration in the UK}

To enhance effective transport administration, the British government has divided the responsibility of transport administration between two national bodies, central or national and the local authorities. The tasks shared at the national level are between the Secretary of State for Transport (for England), the Secretary of state of Scotland, and the Secretary of state for Wales. Permanent civil servants from different departments support each of the preceding. And at the local level tasks are shared with district councils, London boroughs, and county councils.

\subsection{The Department of Transport}

The Department of Transport is the most authoritative in respect for land, sea and air transport. These include support and funding of the rail and bus industries; motorways and trunk roads; airport; domestic and international civil aviation; shipping and the port industry; navigation lights, pilotage, HM, coastguard and marine pollution. The Department gives an oversight of road transport, including registration and licensing; vehicle standards; driver testing and licensing; bus and road freight licensing; regulation of taxis and private hire cars; and road safety.

Because of the nature of road transport infrastructure as one of the significant land uses, strong links abound with the Department for Environment to ensure that livability for the road system within the environment. Moreover, the concern is to make people safe wherever they work and live. The significant areas of intervention for the environment and Transport include the following: planning, local government, new towns, housing, inner-city matters and environmental protection.

The administrative head of the Department of Transport is the Secretary of State for Transport and supported by a Minister of State and two Parliamentarian Under Secretaries for respective transport portfolio assigned for policy initiation and planning across the transport modes.

Public transport services in the UK contrast from region to region and town to town. In some areas, facilities are excellent and good value for money, while in others they're infrequent, slow and expensive. According to an article 'Living and Working in Britain', the UK has no combined universal transport policy, principally a long-term strategy that balances the needs of the public transport user against those of the motorist. The UK's transport 'system' is profoundly biased towards road transport and the level of public transport subsidies in the UK is among the lowest in Europe. Despite more people using public Transport in London than in any other European city (London has the world's largest rail and tube network), it has the most expensive public Transport of any capital city in Europe.

\section{Issues in Transportation Administration}


Over the years, the transportation system in every part of the world has never been without issues. These transport issues vary from one particular nation to the other. The study concentrated on critical aspects found in Nigeria and Britain. And how these have addressed in the course of enhancing their transportation prospect.

\subsection{Transportation Policy}

Globally, one of the fundamental issues affecting the transportation system is the policy issue. According to Rodrigue (2017), the goal of transport policy is to make effective decisions regarding the allocation of transport resources, plus the management and regulation of existing transportation events. Thus, transport policy can be concurrently a public and private endeavour. Still, governments are often the most elaborate in the policy process; meanwhile, they also own or control many components of the transport system and have levels of influence on all existing transportation modes.

While there had been a consistency in the policy formulation and intervention on all modes of Transport in Britain, however, lack of transformative policy template has been the bane of transport system development in Nigeria. Many of the government intervention up till now has not led to transformative policy outcomes. Below are some of the response since independent:

The Stanford Research Institute Study commissioned by the Federal Government in 1961 which set the pace for the statement of Policy on Transport in 1965

The Wey Commission of 1971 which examined the organisation structure of highway development and management in five selected countries and recommended the establishment of the Federal Highway Authority.

The 1979 panel which recommended the setting up of Federal Commissioner of Works and Housing

The 1993 transport policy named moving out of the crisis

The 1996 workshop which launched the Road Vision 2000

The 1999 Presidential Policy Advisory Committee (PPAC) recommended the funding of highway to the establishment of Road Fund

The 2003 Draft, National Transport Policy document, commissioned by the Federal Ministry of Transport to address the visible competition between transport modes especially Road and Rail transport

\subsection{System Performance}

Transportation systems operate at capacity for substantial periods of the day. Within this period, the transportation industry must be adequate to prevent unanticipated crashes, traffic congestion and delay, which could affect motorists, travellers on intercity planes, train and ship users. With the growth in population in every country, an effective system put in place. According to Tischer (2013), Performance management is about connecting goals and 
objectives to resources and results. A significant performance issue across all modes is the inadequacy of preparation for natural and human-made disasters. In Nigeria, dismal performance reflected in the freight traffic fluctuation, low train speed limit, public vehicular Transport and shipping service.

\subsection{Safety in Transport Sector}

The issue of safety in transport administration exists in both the advanced and developing nations. However, the problem of security better managed in the developed nations. Joewono $\&$ Kubota (2006). Contend that the situation becomes more in developing countries because of the lack of suitable and integrated approaches - safety defined as freedom from harm resulting from unintentional acts or circumstances. The major factors responsible for insecurity in transportation in Africa, Latin America and Asia are connected to pure regulation, facility maintenance, overload, inadequate training, ignorance and deliberate disobedient to public transportation laws by users, low road lighting, and bad roads.

\subsection{Provision of Transport Infrastructures}

There is a correlation between an effective transportation system and substantial infrastructure in any country. Hence, importance on transport structure is also apparent in the lending outline of the World Bank, which pledges a larger share of resources to transport infrastructure than education, health and social services combined (World Bank 2007). Huge capital is always needed to be able to accomplish the various infrastructural project plans by the government. According to Muktar (2011), investment in transportation infrastructure is critical to sustained economic growth.

\subsection{Finance}

Transportation administration challenged by inadequate finance. The governments always augment the funds with taxpayers' money, since transportation infrastructures as a public good, placed under the management of public authorities. However, according to Jean-Paul Rodrigue (2017), transport funding initiatives are generally not adequate for maintaining and improving the performance of transport systems. Hence, he concluded by saying this factor was a significant driver behind privatisation and deregulation in the transport system as new competitors entered the market. A vital question confronting different nations in the global community is how to finance the construction of and maintenance of Transport.

\subsection{Increasingly Congested Facilities}

Public Transport and mobility are challenging endeavour in urban areas generally. As city populations grow, and as their socio-economic bases changes, even as more vehicles enter the roads each day. National Express Transit (2017) suggested that one of the practical solutions to decreasing the gravity on city streets and highways is keeping a robust public transportation system. Still, new urban areas carry a host of challenges to the table for transit agencies, some of which can be eased by proper and forward-looking public transport management, and others which will need to come from the municipal level downwards. Likewise, reducing congestion and delay in the airport, seaport and rail transportation 
systems are issues affecting different countries because travel demand has escalated.

\subsection{High Transportation Costs}

Moving cargoes from one location to another is never free. According to Cockburn (2014), the higher the load, the longer the distance, the higher the cost of transportation of goods. Nevertheless, weight and distance are not the only two aspects that affect transportation costs. Several other factors have a significant impact on the cost of transportation such as packaging, fuel prices, inventory carrying costs, security and insurance costs. Recent papers provide suggestive evidence on how lower transportation costs, decrease trade costs and interregional price gaps by enabling greater access to markets (Donaldson 2012, Casaburi et al. 2013).

\subsection{Vulnerability to Terrorist Strikes}

The incident of a terrorist attack is a global issue. However, it is more prevalent in one particular nation than another. Again, terrorist attacks are more rampant in air transportation than other means of transportation facilities - a considerable number of cases reported in the media of air hostages that held travellers in the plane.

The issue of how Nigeria and Britain will ramp up their airports is very crucial to prevent the sudden attack of terrorists whose intention is to bomb the airport or blow up the plane or seaport.

\subsection{Low Revenue Generation}

Another issue in transportation is how to secure revenue for the government in the form of investment returns. This medium becomes an issue because the government transport facilities are cheaper since the citizens' interests have to be put into cognisance regularly in the course of determining what the cost or charges should be. The provision of transportation services expects to be free and cheap, but the value of the investment is always enormous.

\subsection{Capacity Building}

The issue of incompetent, untrained and unlicensed people using their transportation facilities to engage in business activities has been a debate among government officials, public and private investors over the years. The illegal use of those facilities, particularly road transporters, has become a joint development.

\subsection{Low Service Delivery}

The engagement of government in the transportation business is to make life more meaningful and less challenging to the citizens. Thus, government investment in rail, road, sea and air transportation enables the citizen to have access to those facilities.

\section{Discussion}

This study focuses on harnessing the power of effective transport administration to bring about effective Transport infrastructural development. It compares the transport administration practices in Nigeria and the United Kingdom. The transport administrative portfolio in the United Kingdom is more robust and effective in delivering needed reform for 
optimal mobility for residents in the United Kingdom. However, in Nigeria, the implementation and administration of Transport seem ineffective in driving needed reforms for significant mobility in Nigeria.

Besides, the bane of adequate transportation administration on the part of Nigeria is the lack of policy harmonisation on the part of all the agencies responsible for transport policy implementation. The discrepancies identified on the part of Nigeria is responsible for independent hanging policies that lack definite result for physical mobility transformation. The lapses have created a profound shortage of total evaluation and preparation for exact policy build up.

\section{Conclusion}

Transport is an essential factor for socio-economic, cultural and political development in any society irrespective of regions. Because of its importance, its proper administration becomes inevitable by government and stakeholders in every culture, be it Nigeria or Britain. Transport administrators oversee the policy, planning growth and maintenance of transportation systems. The importance of the transport sector articulated by scholars such as (Turok \& McGranahan (2013); Goryakin, Lobstein, Philip, \& MarcSuhrcke, (2015). Britain has benefited significantly from policy, planning and implementation into effective transport administration. However, Nigeria tends to drag too softly in an effective and efficient transport administrative process and procedure. Thus, the transport infrastructure reflected the apparent lack of virile administrative practice in the transport sector of the Nigeria economy.

\section{References}

Adebisi, O. (2004). Transport Systems Management in Nigeria in Vandu-Chikolo et al (eds) Perspectives on Urban Transportation in Nigeria. Nigeria Institute of Transport Technology (NITT), Zaria.

Casaburi, L., Glennerster, R., \& Tavneet, S. (2012). Rural Roads and Intermediated Trade: Regression Discontinuity Evidence from Sierra Leone, MIT Working paper. https://doi.org/10.2139/ssrn.2161643

Cockburn, J. (2014). 5 Issues that could be affecting your transportation costs. Retrieved today Thursday 21 March, 2019 from https://3pllinks.com/5-issues-affecting-transportationcosts/

Donaldson, D., \& Richard H. (2013). Railroads and American economic growth: A market access approach, Working paper. https://doi.org/10.3386/w19213

Goryakin, Y., Lobstein, T., Philip T., MarcSuhrcke, J. (2015). The impact of economic, political and social globalisation on overweight and obesity in the 56 low and middle income countries. Social Science and Medicine, 133(67-76), Elsevier. https://doi.org/10.1016/j.socscimed.2015.03.030

Living and Working in Britain (n.d). Survival Books, United Kingdom.

Mabogunje, A. (2015). The development process: A spatial perspective. Routledge. 
https://doi.org/10.4324/9781315658483

Muktar, M. (2011). Impact of Transportation on Economic Growth: An Assessment of Road and Rail Transport Systems. Retrieved today Saturday, February 16, 2019 from Mustapha Muktar.blogspot.com/2011/01/impact-of-transport-on-economic.html.

National Express Trust/ Transit Operations (2017). 5 Transportation Challenges in Urban areas, Transit Industry Trends. August 17, 2017.

Olukoju, A. (2013). Infrastructure development and urban facilities in Lagos, 1861-2000. IFRA-Nigeria.

Rodrigue, J. P. (2017). The Geography of Transport Systems. New York: Routledge, 440 pages. ISBN 978-1138669574.

Tischer, M. L. (2013). Breaking your performance Management program for reauthorisation. In Measurement of Transportation Systems. Summary of the Fourth International Conference Proceeding, Transportation Research Board Conference Proceedings 49, USA.

Transportation Research Board (TRB, 2019). Critical Issues in Transportation: Policy Snapshot. The National Academies of Sciences, Engineering and Medicine, USA.

Turok, N. \& McGranahan, G. (2013). Urbanisation and economic growth: the arguments and evidence for Africa and Asia. Sage Journal. Retrieved to Thursday 21 March, 2019 fromhttps://journals.sagepub.com/doi/full/10.1177/0956247813490908.

World Bank (2007). Evaluation of World Bank Support to Transportation Infrastructure. Washington DC: World Bank Publications.

\section{Copyright Disclaimer}

Copyright for this article is retained by the author(s), with first publication rights granted to the journal.

This is an open-access article distributed under the terms and conditions of the Creative Commons Attribution license (http://creativecommons.org/licenses/by/4.0/). 